Hiroyuki Ohmori • Yoshio Makita • Makiko Funamizu

Shin-ichi Chiba · Katsuki Ohtani • Yasuhiko Suzuki

Nobutaka Wakamiya • Akira Hata

\title{
Haplotype analysis of the human collectin placenta 1 (hCL-P1) gene
}

\begin{abstract}
Collectins are a family of C-type lectins found in vertebrates. These proteins have four regions, a relatively short N-terminal region, a collagen-like region, an alphahelical coiled coil, and a carbohydrate recognition domain. Collectins are involved in host defense through their ability to bind carbohydrate antigens on microorganisms. Type A scavenger receptors are classical-type scavenger receptors that also have collagen-like domains. We previously described a new scavenger receptor, collectin from placenta [collectin placenta 1 (CL-P1)]. CL-P1 is a type II membrane protein with all four regions. We found that CL-P1 can bind and phagocytize both bacteria and yeast. In addition to that, it reacts with oxidized low-density lipoprotein (LDL) but not with acetylated LDL. These results suggest that CL-P1 might play important roles in host defenses and/or atherosclerosis formation. One rational strategy to study the role of CL-P1 in these pathological conditions would be to perform a haplotype association study using human samples. As a first step for this strategy, we analyzed the haplotype structure of the $C L-P 1$ gene. By sequencing the $C L-P 1$ gene in ten Japanese volunteers, we identified five singlenucleotide polymorphisms (SNPs) with a minor allele frequency of at least $29 \%$. To obtain SNPs in the 5'-upstream region of the gene, we screened a total of 20 SNPs described
\end{abstract}

H. Ohmori $\cdot$ Y. Makita $\cdot$ M. Funamizu $\cdot$ S. Chiba $\cdot$ A. Hata ${ }^{1}(\bowtie)$ Department of Public Health, Asahikawa Medical College, 2-1-1-1 Midorigaoka-higashi, Asahikawa 078-8510, Japan

Tel. +81-166-68-2410; Fax +81-166-68-2419

K. Ohtani · N. Wakamiya

Department of Microbiology, Asahikawa Medical College, Asahikawa, Japan

Y. Suzuki

Department of Pathology, Osaka Prefectural Institute of Public Health, Osaka, Japan

\footnotetext{
Present address

${ }^{1}$ Department of Public Health, Graduate School of Medicine, Chiba University, 1-8-1 Inohana, Chuo-ku, Chiba 260-8670, Japan

Tel. +81-43-226-2067; Fax +81-43-226-2070

e-mail: ahata@med.m.chiba-u.ac.jp
}

in the database and finally picked up one SNP for the present study. Thus, a total of six SNPs, one in the 5'upstream region, two in intron 2 , one in exon 5 , and two in exon 6 , were used to analyze the haplotype structure of the gene, with DNAs derived from 54 individuals (108 alleles). The analysis revealed that only two of six SNPs showed significant linkage disequilibrium $\left(r^{2}>0.5\right)$ with each other. This haplotype information may be useful in disease-association studies in which a contribution of the CL-P1 gene has been suspected, especially in immunological disturbance or atherosclerosis. Two SNPs in exon 6, both leading to amino acid substitutions, could be candidates for influencing disease susceptibility.

Key words Single-nucleotide polymorphisms · Linkage disequilibrium - Haplotype - Collectin - Japanese population · Host defense $\cdot$ Amino acid substitution $\cdot$ Atherosclerosis

\section{Introduction}

Collectins are a family of proteins that contain a collagenlike region and a carbohydrate recognition domain (CRD) (Drickamer 1988). Collectins are found in vertebrates including avians (Laursen et al. 1998). There are four groups of collectins: a mannan-binding protein (MBP) group, two lung surfactant groups of surfactant protein A (White et al. 1985) and surfactant protein D (SP-D) (Persson et al. 1989), and a newly isolated group, collectin liver 1 (Ohtani et al. 1999) and collectin placenta 1 (CL-P1) (Ohtani et al. 2001). Collectins are known to be involved in innate immunity through various mechanisms, for example, by activation of the complement pathway (Kawasaki et al. 1989), by opsonization via collectin receptors (Schweinle et al. 1989; van Iwaarden et al. 1992), and by amplification of phagocytosis by macrophages (Pikaar et al. 1995). Interestingly, the type A scavenger receptor (SR-A) also contains a collagenlike domain (Kodama et al. 1990), which could bind and destruct pathogens by endocytosis and phagocytosis. In fact, recent data with SR-A1 knock-out mice (Suzuki et al. 
1997) support the possibility that scavenger receptors also have a role in innate immunity.

Recently, we cloned and characterized the human $C L$ $P 1$ gene ( $h C L-P 1)$, and found that it was a membrane-type collectin that functions as a scavenger receptor. The major tissue expression of the gene was endothelial cells but not in monocyte-macrophage lineage cells. We also found that CL-P1 was able to bind and phagocytose bacteria and yeast as well as oxidized low-density lipoprotein (Ohtani et al. 2001). With these results, we hypothesized that this gene could play an important role in the human innate immunity system and/or atherosclerosis formation. To study this possibility, we are collecting human samples that are susceptible to infection, especially in childhood, and also samples from patients with atherosclerosis without lipid profile abnormalities. Haplotype association studies would be the best choice for this purpose. Here, we report the haplotype structure of the $C L-P 1$ gene obtained from six singlenucleotide polymorphisms (SNPs) that were genotyped with 108 alleles in Japanese subjects.

\section{Subjects and methods}

\section{Identification of SNPs}

To identify useful SNPs in the gene region, we sequenced amplified DNAs derived from ten Japanese volunteers (20 alleles). Polymerase chain reaction (PCR) primers were chosen at approximately 500-bp intervals, with about an 80 bp overlap (Shinohara et al. 2001). A total of 16 primer sets were designed based on the information obtained from a public genome database (AC022545, AP000925, AP001005, http://www.ncbi.nlm.nih.gov/) to amplify all 10 exons; 5'flanking regions; and introns 1, 4, 6, 7, and 9. Other introns were sequenced in the regions near exon-intron boundaries. After amplification, a sequencing reaction was performed and analyzed on an ABI 310 genetic analyzer (PE Biosystems, Foster City, CA, USA). SNPs were detected by alignment of the sequencing data of ten individuals. To obtain SNPs in the $5^{\prime}$-upstream region, we analyzed 20 SNPs described in the publicly available SNP database of The SNP Consortium Ltd (TSC; http://snp.cshl.org/ index.html) with 20 Japanese alleles.

\section{SNP genotyping}

SNPs were genotyped using three PCR-based methods: single-strand conformational polymorphism (SSCP), SNaPshot, and sequencing. PCR was performed in a volume of $12.5 \mu \mathrm{l}$ containing $20 \mathrm{ng}$ genomic DNA, $75 \mathrm{mM}$ Tris HCL (pH 8.8), $20 \mathrm{mM}\left(\mathrm{NH}_{4}\right)_{2} \mathrm{SO}_{4}, 0.01 \%$ Tween 20 , $1.5 \mathrm{mM} \mathrm{MgCl} 2,200 \mu \mathrm{M}$ deoxyribonucleotide triphosphates (dNTPs), 10 pmol of each primer, and 0.25 units of Taq polymerase. PCR amplification was performed through 30 cycles of $94^{\circ} \mathrm{C}$ for $30 \mathrm{~s}, 49^{\circ}-62^{\circ} \mathrm{C}$ for $30 \mathrm{~s}$, and $72^{\circ} \mathrm{C}$ for $30 \mathrm{~s}$, depending on the region analyzed, with a final extension step of $5 \mathrm{~min}$ at $72^{\circ} \mathrm{C}$ in a Gene Amp PCR9700 System (PE
Biosystems). For SSCP analysis, each $2.5 \mu \mathrm{l}$ of PCR products were mixed with formamide dye and heat denatured, and then applied to polyacrylamide gel electrophoresis. After electrophoresis, the gel was silver stained (Wako Pure Chemical, Tokyo, Japan) to detect polymorphic bands. A SNaPshot primer extension method was performed following the manufacturer's instructions (PE Biosystems). To obtain a purified template for $\mathrm{SNaPshot}$ and sequencing, we removed dNTPs and primers from amplified genomic DNA by means of ExoSAP-IT (USB, Cleveland, OH, USA). In the case of the SNaPshot method, reaction mixtures were electrophoresed on an ABI 310 genetic analyzer and data were analyzed with GeneScan software (PE Biosystems). For haplotype analysis, a total of 54 DNA samples (108 alleles) of healthy volunteers, recruited in our medical school, were genotyped. All of them were medical students and gave their informed consent. The Ethics Committee of Asahikawa Medical College approved this study.

\section{Haplotype analysis}

Estimation of haplotype frequency was performed by the maximum-likelihood method using SNPAlyze (DYNACOM, Yokohama, Japan, http://www. dynacom.co.jp/).

\section{Results and discussion}

By sequencing the $C L-P 1$ gene region of ten Japanese volunteers (20 alleles), we identified five SNPs, two in intron 2 (SNP2, SNP3), one in exon 5 (SNP4), and two in exon 6 (SNP5, SNP6; Fig. 1, Table 1). In consideration of their importance in gene regulation, 20 SNPs were screened by sequencing the $5^{\prime}$-upstream region described in The SNP Consortium Ltd database. SNP1 was shown to be useful for our purposes. A total of six SNPs were used for genotyping and haplotype analysis. Genotype and allele frequencies of six SNPs and their location in the gene are shown in Table 1. All genotype frequencies conformed to Hardy-Weinberg equilibrium. Genotyping of 54 individuals (108 alleles) revealed that all SNPs are quite common, the minor allele frequency being at least $29 \%$.

Of six SNPs, three (SNP4-6) are located in the coding region, one silent mutation is located in exon 5 (SNP4: T267T), and two missense mutations are located in exon 6 (SNP5: S522P, SNP6: G606S; Table 1). As shown in Fig. 1, the SNP5 in exon 6 is in the collagen-like domain that has a characteristic Gly-X-Y repetitive pattern, in which $\mathrm{X}$ and $\mathrm{Y}$ can be any amino acid but are frequently prolines or hydroxyprolines. SNP5, either serine or proline, located in the $\mathrm{X}$ position, could have some affect on the stability of collagen structure. In fact, in the $M B P$ gene, which belongs to one of the collectin groups and is known to have a significant role in innate host immunity, three relatively common mutations in the homotrimeric region have been reported to be associated with invasive pneumococcal disease (Roy 


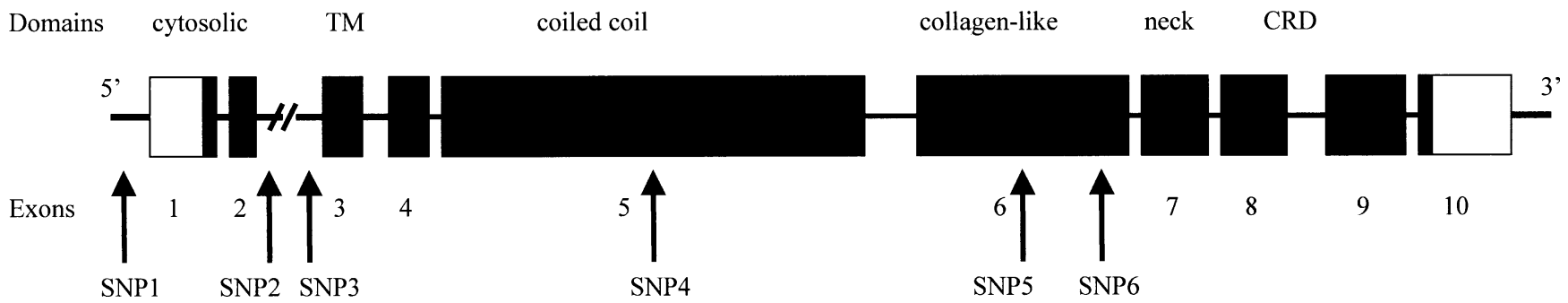

Fig. 1. Relationship between genomic structure and the location of single-nucleotide polymorphisms $(S N P S)$ in the human $C L-P 1$ gene. Vertical rectangles and horizontal lines represent exons and introns, respectively. Coding regions are shown with filled rectangles. Arrows

indicate appproximate position of each SNP. Functional domains are indicated above the gene. TM, Transmembrane domain; CRD, carbohydrate recognition domain

Table 1. Genotype and allele frequencies of six SNPs in Japanese subjects

\begin{tabular}{|c|c|c|c|c|c|c|c|c|c|}
\hline \multirow{2}{*}{$\frac{\text { Polymorphism }}{\text { SNP1 (5' upstream region) }}$} & \multirow{2}{*}{$\frac{\text { Nucleotide position }}{-4078^{\mathrm{a}}}$} & \multirow[t]{2}{*}{ Amino acid } & \multicolumn{3}{|c|}{ Genotype } & \multicolumn{2}{|c|}{ Allele } & \multicolumn{2}{|c|}{ Allele frequency } \\
\hline & & & $\begin{array}{l}\mathrm{TT} \\
22\end{array}$ & $\begin{array}{l}\text { TG } \\
24\end{array}$ & $\begin{array}{l}\text { GG } \\
8\end{array}$ & $\begin{array}{l}\mathrm{T} \\
68\end{array}$ & $\begin{array}{l}\mathrm{G} \\
40\end{array}$ & $\begin{array}{l}\mathrm{T} \\
0.63\end{array}$ & $\begin{array}{l}\mathrm{G} \\
0.37\end{array}$ \\
\hline SNP2 (intron 2) & $\mathrm{IVS} 2+814 \mathrm{G}>\mathrm{A}^{\mathrm{b}}$ & & $\begin{array}{l}\text { GG } \\
21\end{array}$ & $\begin{array}{l}\text { GA } \\
24\end{array}$ & $\begin{array}{l}\text { AA } \\
9\end{array}$ & $\begin{array}{l}\mathrm{G} \\
66\end{array}$ & $\begin{array}{l}\text { A } \\
42\end{array}$ & $\begin{array}{l}\mathrm{G} \\
0.61\end{array}$ & $\begin{array}{l}\text { A } \\
0.39\end{array}$ \\
\hline SNP3 (intron 2) & IVS2-1619A $>G^{b}$ & & $\begin{array}{l}\text { AA } \\
24\end{array}$ & $\begin{array}{l}\mathrm{AG} \\
24\end{array}$ & $\begin{array}{l}\text { GG } \\
6\end{array}$ & $\begin{array}{l}\text { A } \\
72\end{array}$ & $\begin{array}{l}\mathrm{G} \\
36\end{array}$ & $\begin{array}{l}\text { A } \\
0.67\end{array}$ & $\begin{array}{l}0.59 \\
G \\
0.33\end{array}$ \\
\hline SNP4 (exon 5) & $800+1 C>T^{b}$ & $\mathrm{~T} 267 \mathrm{~T}$ & $\begin{array}{l}\mathrm{CC} \\
28\end{array}$ & $\begin{array}{l}\text { CT } \\
21\end{array}$ & $\begin{array}{l}\text { TT } \\
5\end{array}$ & $\begin{array}{l}\mathrm{C} \\
77\end{array}$ & $\begin{array}{l}\mathrm{T} \\
31\end{array}$ & $\begin{array}{l}\mathrm{C} \\
0.71\end{array}$ & $\begin{array}{l}\mathrm{T} \\
0.29\end{array}$ \\
\hline SNP5 (exon 6) & $1563+1 \mathrm{C}>\mathrm{T}^{\mathrm{b}}$ & S522P & $\begin{array}{l}\mathrm{CC} \\
27\end{array}$ & $\begin{array}{l}\text { CT } \\
23\end{array}$ & $\begin{array}{l}\text { TT } \\
4\end{array}$ & $\begin{array}{l}\mathrm{C} \\
77\end{array}$ & $\begin{array}{l}\mathrm{T} \\
31\end{array}$ & $\begin{array}{l}\mathrm{C} \\
0.71\end{array}$ & $\begin{array}{l}\mathrm{T} \\
0.29\end{array}$ \\
\hline SNP6 (exon 6) & $1815+1 \mathrm{~A}>\mathrm{G}^{\mathrm{b}}$ & G606S & $\begin{array}{l}\text { GG } \\
23\end{array}$ & $\begin{array}{l}\text { GA } \\
27\end{array}$ & $\begin{array}{l}\text { AA } \\
4\end{array}$ & $\begin{array}{l}G \\
73\end{array}$ & $\begin{array}{l}\text { A } \\
35\end{array}$ & $\begin{array}{l}\mathrm{G} \\
0.68\end{array}$ & $\begin{array}{l}\text { A } \\
0.32\end{array}$ \\
\hline
\end{tabular}

SNP, Single-nucleotide polymorphism

${ }^{a}$ Nucleotide position is identified from the translation initiation site

${ }^{\mathrm{b}}$ The designation of other SNPs follows the recommendation of mutation nomenclature in Dunnen and Antonarakis (2000)

et al. 2002). Although two of the three mutations, those in codons 54 and 57, located in the Gly position, the remaining mutation in codon 52 is located at the $\mathrm{X}$ position, which exchange the amino acid cysteine for arginine. In terms of SNP6 in exon 6, either glycine or serine is located in the neck domain. Hydrophobic amino acids in the neck domain contribute to form an alpha-helical coiled coil. A coiled-coil structure can be recognized by its characteristic heptad repeat pattern a-b-c-d-e-f-g, in which "a" and "d" are hydrophobic residues. Each alpha-helix interacts with a neighboring CRD (Sheriff et al. 1994). Human MBP and SP-D have such heptad repeats in the neck domain (Zhang et al. 2001). However, in the case of hCL-P1, the neck domain of 17 amino acid residues does not have a characteristic heptad structure. Even so, both collagen-like domain and CRD have a collaborative role in recognizing pathogens, and an amino acid alteration in the neck domain might still have some influence.

The result of linkage disequilibrium (LD) analysis is summarized in Table 2. Among the SNPs, only SNP4 and SNP5 showed significant LD $\left(r^{2}=0.823\right)$. Haplotype frequencies among 108 alleles were calculated (Table 3). The top eight haplotypes with frequencies over $5 \%$ accounted for $67 \%$ of all haplotypes.

CL-P1 is a member of the collectin family, which is considered to play significant roles in innate immunity. Classical collectins are soluble, but CL-P1 is membrane bound.
Table 2. Analysis of linkage disequilibrium for all possible two-way comparisons among six SNPs

\begin{tabular}{lllllll}
\hline & SNP1 & SNP2 & SNP3 & SNP4 & SNP5 & SNP6 \\
\hline SNP1 & $D^{\prime}$ & 0.040 & 0.659 & 0.144 & 0.245 & 0.208 \\
& $r^{2}$ & 0.001 & 0.119 & 0.005 & 0.014 & 0.012 \\
& $P$ & 0.822 & 0.000 & 0.534 & 0.287 & 0.279 \\
SNP2 & & $D^{\prime}$ & 0.003 & 0.226 & 0.145 & 0.003 \\
& & $r^{2}$ & 0.000 & 0.032 & 0.013 & 0.000 \\
& & $P$ & 0.822 & 0.040 & 0.236 & 0.822 \\
SNP3 & & & $D^{\prime}$ & 0.325 & 0.437 & 0.092 \\
& & & $r^{2}$ & 0.092 & 0.167 & 0.008 \\
& & & $P$ & 0.001 & 0.000 & 0.351 \\
SNP4 & & & & $D^{\prime}$ & 0.907 & 1.000 \\
& & & & $r^{2}$ & 0.823 & 0.195 \\
& & & & & 0.000 & 0.000 \\
SNP5 & & & & & $D^{\prime}$ & 1.000 \\
& & & & & $P$ & 0.195 \\
& & & & & & \\
\hline
\end{tabular}

CL-P1 might bind and control not only bacteria and yeasts, but also modified LDLs in the vascular space. The collagenlike domains in human and mouse CL-P1, which have the highest identity (96\%) described to date, may play the most important role in these biological functions (Ohtani et al. 2001).

In conclusion, these six polymorphisms, their haplotype, and the state of LD will the useful for investigation of a possible relationship between genetic variation at the 
Table 3. Frequencies of haplotypes constructed from six SNPs

\begin{tabular}{lllllll}
\hline SNP1 & SNP2 & SNP3 & SNP4 & SNP5 & SNP6 & \\
TG & AG & GA & TC & CT & GA & Frequency \\
\hline G & G & A & C & C & G & 0.155 \\
T & G & G & T & T & G & 0.114 \\
T & G & A & C & C & G & 0.091 \\
T & G & A & C & C & A & 0.074 \\
T & G & G & C & C & A & 0.060 \\
T & A & A & C & C & G & 0.059 \\
G & A & A & T & T & G & 0.053 \\
T & A & G & C & C & A & 0.053 \\
G & A & A & C & C & A & 0.049 \\
G & G & A & C & C & A & 0.046 \\
T & A & A & C & C & A & 0.038 \\
T & A & A & T & T & G & 0.037 \\
T & G & A & T & T & G & 0.032 \\
G & A & A & C & C & G & 0.026 \\
T & A & G & T & T & G & 0.021 \\
T & G & G & C & T & G & 0.019 \\
G & A & G & T & T & G & 0.016 \\
T & G & G & C & C & G & 0.013 \\
G & A & G & C & C & G & 0.012 \\
T & A & G & C & C & G & 0.012 \\
G & A & A & T & C & G & 0.009 \\
T & A & A & T & C & G & 0.009 \\
& & & & & Total & 1.000 \\
\hline
\end{tabular}

human $C L-P 1$ locus and human diseases, especially in association studies between specific polymorphisms and susceptibility to innate immunity disease or atherosclerosis.

Acknowledgments We are grateful to Katsura Nakanishi and Ayako Sado for their technical assistance. This work was supported by Grantin-Aid for Scientific Research on Priority Areas (C) "Medical Genome Science" from the Ministry of Education, Culture, Sports, Science, and Technology of Japan.

\section{References}

Drickamer K (1988) Two distinct classes of carbohydrate-recognition domains in animal lectins. J Biol Chem 263:9557-9560

Dunnen JT, Antonarakis SE (2000) Mutation nomenclature extensions and suggestions to describe complex mutations: A discussion. Hum Mutat 15:7-12

van Iwaarden JF, van Strijp JA, Visser H, Haagsman HP, Verhoef J, van Golde LM (1992) Binding of surfactant protein A (SP-A) to herpes simplex virus type 1 -infected cells is mediated by the carbohydrate moiety of SP-A. J Biol Chem 267:25039-25043

Kawasaki N, Kawasaki T, Yamashina I (1989) A serum lectin (mannan-binding protein) has complement-dependent bactericidal activity. J Biochem (Tokyo) 106:483-489
Kodama T, Freeman M, Rohrer L, Zabrecky J, Matsu-daira P, Krieger M (1990) Type I macrophage scavenger receptor contains alphahelical and collagen-like coiled coils. Nature 343:531-535

Laursen SB, Dalgaard TS, Thiel S, Lim BL, Jensen TV, Juul-Madsen HR, Takahashi A, Hamana T, Kawakami M, Jensenius JC (1998) Cloning and sequencing of a cDNA encoding chicken mannan-binding lectin (MBL) and comparison with mammalian analogues. Immunology 93:421-430

Ohtani K, Suzuki Y, Eda S, Kawai T, Kase T, Yamazaki H, Shimada T, Keshi H, Sakai Y, Fukuoh A, Sakamoto T, Wakamiya N (1999) Molecular cloning of a novel human collectin from liver (CL-L1). J Biol Chem 274:13681-13689

Ohtani K, Suzuki Y, Eda S, Kawai T, Kase T, Keshi H, Sakai Y, Fukuoh A, Sakamoto T, Itabe H, Suzutani T, Ogasawara M, Yoshida I, Wakamiya N (2001) The membrane-type collectin CL-P1 is a scavenger receptor on vascular endothelial cells. J Biol Chem 276:44222-44228

Persson A, Chang D, Rust K, Moxley M, Longmore W, Crouch E (1989) Purification and biochemical characterization of CP4 (SP-D), a collagenous surfactant-associated protein. Biochemistry 28:63616367

Pikaar JC, Voorhout WF, van Golde LM, Verhoef J, Van Strijp JA, van Iwaarden JF (1995) Opsonic activities of surfactant proteins $\mathrm{A}$ and $\mathrm{D}$ in phagocytosis of gram-negative bacteria by alveolar macrophages. J Infect Dis 172:481-489

Roy S, Knox K, Segal S, Griffiths D, Moore CE, Welsh KI, Smarason A, Day NP, McPheat WL, Crook DW, Hill AVS, Oxford Pneumococcal Surveillance Group (2002) MBL genotype and risk of invasive pneumococcal disease: a case-control study. Lancet 359:1569-1573

Schweinle JE, Ezekowitz RA, Tenner AJ, Kuhlman M, Joiner KA (1989) Human mannose-binding protein activates the alternative complement pathway and enhances serum bactericidal activity on a mannose-rich isolate of Salmonella. J Clin Invest 84:1821-1829

Sheriff S, Chang CY, Ezekowitz RA (1994) Human mannose-binding protein carbohydrate recognition domain trimerizes through a triple alpha-helical coiled-coil. Nat Struct Biol 1:789-794

Shinohara Y, Ezura Y, Iwasaki H, Nakazawa I, Ishida R, Kodaira M, Kajita M, Shiba T, Emi M (2001) Linkage disequilibrium and haplotype analysis among ten single-nucleotide polymorphisms of interleukin 11 identified by sequencing of the gene. J Hum Genet 46:494-497

Suzuki H, Kurihara Y, Takeya M, Kamada N, Kataoka M, Jishage K, Ueda O, Sakaguchi H, Higashi T, Suzuki T, Takashima Y, Kawabe Y, Cynshi O, Wada Y, Honda M, Kurihara H, Aburatani H, Doi T, Matsumoto A, Azuma S, Noda T, Toyoda Y, Itakura H, Yazaki Y, Horiuchi S, Takahashi K, Kruijt JK, Berkel TJC, Steinbrcher UP, Ishibashi S, Maeda N, Gordon S, Kodama T (1997) A role for macrophage scavenger receptors in atherosclerosis and susceptibility to infection. Nature 386:292-296

Wakamiya N, Okuno Y, Sasao F, Ueda S, Yoshimatsu K, Naiki M, Kurimura T (1992) Isolation and characterization of conglutinin as an influenza A virus inhibitor. Biochem Biophys Res Commun 187:1270-1278

White RT, Damm D, Miller J, Spratt K, Schilling J, Hawgood S, Benson B, Cordell, B (1985) Isolation and characterization of the human pulmonary surfactant apoprotein gene. Nature 317:361-363

Zhang P, McAlinden A, Li S, Schumacher T, Wang H, Hu S, Sandell L, Crouch E (2001) The amino-terminal heptad repeats of the coiledcoil neck domain of pulmonary surfactant protein $\mathrm{d}$ are necessary for the assembly of trimeric subunits and dodecamers. J Biol Chem 276:19862-19870 